\title{
TORNAR-SE PROFESSORA NO ESTÁGIO SUPERVISIONADO: UM PROCESSO DE IMPLICAÇÃO E ATUAÇÃO
}

\author{
Adriana Varani ${ }^{1}$ \\ Sara Badra de Oliveira ${ }^{2}$
}

Tomar o trabalho pedagógico realizado na escola e na aula como espaço de produção de saberes, de culturas, de relações e consequentemente de conhecimento é um dos princípios com os quais trabalhamos nos processos de orientação de estágio. E reconhecê-lo como tal é reconhecer que estudantes e equipe escolar são sujeitos nesta produção e não meros consumidores de conhecimento. Se tomarmos esta premissa, o professor em formação, enquanto estagiário, também está inserido neste universo. Não são meros observadores do trabalho pedagógico, estão implicados no aprender em movimento. Orientar estágios em que os estudantes estão na escola na condição de professor em formação tem nos propiciado perceber o quanto é necessário problematizar e complexificar as práticas realizadas a fim de que nos coloquemos e nos impliquemos nas relações de ensino. Este processo de complexificar tem nos mostrado o quanto a dimensão das teorias educacionais se significa e se re-significa, tomando novos contornos e novos sentidos para os futuros professores, bem como para a própria universidade (SMOLKA, 1993).

O estágio assim não se configura meramente como um espaço de aprender um conjunto de técnicas de ensino com outros professores, mas de problematizá-las, bem como problematizar as relações em que estão envolvidas, considerando as condições estruturais, as políticas educacionais, a diversidade dos sujeitos em formação e das interações estabelecidas, além do conhecimento e da cultura em jogo. Com nosso trabalho induzimos um processo de rompimento com a velha dicotomia teoria e prática, com a velha ideia de que a prática está numa dimensão menor no quadro da formação. E que sem ela a teoria não se significa. Isto ocorre porque pensamos a prática e teoria imersas no emaranhado destas relações.

Há um conjunto de referências que nos formam e constituem o nosso trabalho. Nossas referências teóricas também fazem parte deste conjunto, por isso é importante relevá-las no processo formativo. Freitas (1991) nos alerta para o fato de que não é a teoria que na prática é outra, mas que muitas vezes a teoria estudada na prática não convém. Não convém, primeiramente porque para ele a teoria não é criada sem diálogo com a prática e, segundo, é que muitas vezes uma teoria estudada, produzida, porque contextualizada em um paradigma social, histórico, não convém a uma forma de produção histórica da escola.

É nesta leitura sobre relação e movimento dos alunos no cotidiano da escola, repleto de muitos significados e mediante um projeto histórico de escola e educação que não deveria provocar a exclusão e subordinação das pessoas, é que construímos a nossa proposta.

Com esta perspectiva nos organizamos na disciplina EP 911, Estágio Supervisionado II Anos iniciais do Ensino Fundamental. Na tentativa de inverter uma lógica que permanece fortemente nos momentos de estágio, propusemos construir um olhar crítico para o campo de estágio e também propositivo. E este olhar teria dois movimentos básicos.

O primeiro foi deslocar o olhar restrito para a metodologia do trabalho em aula e direcioná-lo para as relações estabelecidas, para as produções das crianças, para sua relação com a metodologia adotada em aula, e com aspectos das políticas educacionais, na perspectiva

\footnotetext{
${ }^{1}$ Universidade Estadual de Campinas.

${ }^{2}$ Universidade Estadual de Campinas.
} 
de potencializar a compreensão da singularidade dos indivíduos que participam do processo de ensino-aprendizagem, no diálogo com aspectos mais amplos.

O segundo movimento foi a construção de uma condução do estágio em que os futuros professores se implicassem no processo. Não apenas um estágio de dizer do outro, mas de se dizer com o outro. Um estágio que buscasse romper com o movimento em que se aprende teoria na universidade e depois, como "um prato de sobremesa" (ARROYO, 1987), se vai aplicar na escola a teoria aprendida, em que apenas vai se "estender" o conhecimento de um lugar para outro. Em outra perspectiva, visamos ressaltar a importância da construção conjunta de saberes, em que o aluno estagiário e os educadores da escola se "comunicam" a respeito do "objeto cognoscível", refletem juntos sobre os determinantes da realidade que os circunda, elaboram em conjunto conhecimentos, e atuam sobre as circunstâncias com objetivo de transformá-las (FREIRE, 1983).

Nessa perspectiva, enfatizamos a necessidade de os alunos estagiários assumirem determinadas posturas: sempre de estarem se movimentando com o/a professor/a, dispondo-se ao trabalho, participando com as crianças nas atividades, realizando atividades propostas pelo/as professore/s. Neste segundo movimento, então, encaixa-se o trabalho de planejamento e implantação de um projeto de atuação.

O projeto de atuação seria realizado em comum acordo com a professora da turma estagiada e seria desenvolvido a partir de um tema pertinente ao grupo e à escola. Orientamos que os alunos de estágio deveriam pensar sua proposta de atuação, bem como olhar para a organização do trabalho pedagógico da escola, tendo como prisma a perspectiva da formação humana.

Encaramos a formação humana como o processo pelo qual o homem se torna humano, a partir da sua interação com a natureza e com os outros homens, natureza aqui entendida como aquela modificada, que incorpora progressivamente as realizações e intervenções humanas. Conforme o homem se apropria, pela educação em sentido amplo, desse conjunto das realizações humanas, ele se forma enquanto ser social e cultural, ao mesmo tempo em que desenvolve suas potências para formar e transformar as circunstâncias nas quais vive. Assim, o homem é visto, nessa perspectiva, como um sujeito histórico e social, formado pelas circunstâncias sociais e também formador de tais circunstâncias, apropriador e também produtor de cultura e de conhecimento.

Não consideramos assim, no contexto escolar, um ser que se restringe ao âmbito da aquisição de conhecimento historicamente produzido, mas sujeito de produção do mesmo. Consideramos também que, para esta produção, o sujeito necessita dispor de todas as suas potencialidades. Ele é entendido como ser multidimensional na produção, logo, na escola, é necessário que mobilize esta multidimensionalidade. Ao exercer o trabalho vital socialmente útil, o homem coloca em movimento todas as suas capacidades e potências, do intelecto ao corpo, seu senso criativo, estético, ético, político. Como preconiza o direito à educação, o sujeito deve ter acesso à formação plena integral (ARROYO, 2013) como ser humano, histórico, social, cultural, ético, corpóreo, de diferentes linguagens, estético, de memória, de imaginação, sensibilidade, de identidades individuais e coletivas.

Nesse sentido, pedimos que os alunos estagiários refletissem sobre como a organização do trabalho pedagógico da escola, seus tempos e espaços, seus processos de gestão e suas relações, trabalhavam ou deixavam de lado o trabalho com a formação humana dos alunos. A centralidade temática do nosso trabalho foi, então, em torno da perspectiva de refletir sobre a integralidade da formação do homem no cotidiano escolar. Orientamos que esse olhar deveria estar presente na proposta de atuação que os estagiários elaborariam juntamente com o professor, bem como no olhar lançado para compreender a estrutura escolar.

Das propostas de atuação elaboradas, evidenciamos como os estudantes exercitaram constituir outra dinâmica de aula. Um dos projetos trabalhou o tema fauna e flora da Mata 
Atlântica a partir de animais empalhados do museu de ciências da Unicamp, que o estagiário levou à escola para propiciar um momento em que os alunos pudessem "observar, tocar, experimentar". Apesar do "ambiente estimulador", em geral a dinâmica da aula foi conduzida na forma de exposição aos alunos das categorizações dos tipos de plantas e animais, discutindo sua importância para a preservação do ecossistema. Outra proposta foi a do trabalho com o gênero textual da história em quadrinhos em que, além da identificação dos elementos que compõem quadrinho - oferecendo aos alunos ferramentas para saberem lidar com essa forma específica de contar história -, trabalhou também com o estímulo para que eles próprios criassem seus personagens, na forma de desenho e de descrição, e posteriormente montassem uma história em quadrinhos própria, com os personagens já existentes e aqueles recriados.

Com a intenção de "Proporcionar um resgate às memórias de outros tempos e sociedades, conhecer a história do município", um terceiro projeto teve como intenção não passar informações sobre uma época passada, mas criar estratégias para fazê-los entender que também estão inseridos no campo de produção de conhecimento. Eles mesmos fizeram um resgate da história, por meio de técnicas de pesquisa (seleção de materiais, entrevistas), e nessa reconstrução puderam perceber que a sociedade nem sempre foi do jeito que é; ao invés, passa por contínuos processos de transformação. O quarto projeto buscou trabalhar a questão da sustentabilidade, por meio de rodas de conversa sobre o tema, pesquisa de imagens que revelassem formas de desrespeito ao meio ambiente, e produção de cartazes de conscientização. Para finalizar, os alunos realizaram uma oficina de papel machê. É interessante observar que os alunos, além de se apropriarem de conceitos como sustentabilidade, consumismo, desperdício, envolveram-se em um trabalho que desenvolveu tanto conhecimentos técnicos a respeito do manuseio de materiais, como uma atuação ética e responsável perante a sociedade.

Ao final dos projetos, alguns depoimentos nos levam a refletir sobre como foi o processo de implicação dos estagiários. Erika diz que o trabalho a transformou a partir do conhecimento de uma prática mais humanizadora da professora que a supervisionou na escola.

Vivenciei de perto uma prática possível de educação que se concebe como resposta responsável, pois garante o conhecimento do mundo e o reconhecimento do outro. Conhecer e estar nesse ambiente, como em toda relação social, me transformou. (...) em minha prática em aprender a ser professora, procurei enxergar o aluno em suas múltiplas dimensões, e não só vê-lo como alguém para quem eu deva "passar" conhecimentos (RIGHI, 2015).

Nas descrições de seu diário de campo, Robson relata as alegrias de ter vivenciado crianças evoluindo em seu processo de alfabetização, mas também se atenta às minúcias das relações entre as crianças, do seu agir ético com o outro, das suas condições de vida, buscando sempre essa postura cuidadosa de escuta que observa as ações do outro, as falas, os comportamentos, os choros e risos, os não-ditos, e os interpreta a partir da compreensão de suas vivências. A partir disso, Robson sentia-se responsável por conversar com essas crianças e tentar confortá-las e colocá-las em situações de aprendizagem.

Muitas coisas neste estágio me fizeram e vem me fazendo imergir profundamente no meu papel histórico, como sujeito de responsabilidade histórica e social (...) Outra dimensão, que tentei auscultar como prática de alteridade foram os olhares e sentimentos daquelas crianças, que são sujeitas da sua própria materialidade histórica, e não tábua rasa, esperando passivamente serem preenchidas de cultura (FREIRE, 2000; 2002). Tive o maior sentimento de esperança e de acreditar que sou capaz de compor um mundo de significado 
com elas. Em educação, em especial na pedagogia, me reencontrei como sujeito potente e capaz de mudar o mundo; por que esse mundo está dentro de mim (...). Tive o maior sentimento de esperança e de acreditar que sou capaz de compor um mundo de significado com elas (SAMPAIO, 2015).

Essas reflexões e projetos desenvolvidos pelos alunos estagiários nos colocaram na tentativa de inverter a marcha de uma escola que, dada sua configuração de tempos, espaços e currículo prescrito, orienta-se pela compreensão de que a criança está na escola para trabalhar sua dimensão cognitiva no sentido restrito de apropriar-se de um conhecimento transmitido, e dessa forma reproduz a divisão social do trabalho, ainda impertinentemente presente em nossa sociedade, entre aqueles que pensam e aqueles que fazem, entre teoria e prática, entre pensar e agir. Esta configuração nos impele a frequentemente movimentar práticas de reprodução a despeito de nosso processo formativo ou de movimentar práticas de resistências. São as últimas que tentamos trabalhar com os estudantes futuros professores no curso de Pedagogia.

Em decorrência do nosso trabalho de orientação de estágio temos nos deparado com desafios e potencialidades. Um dos desafios a ser frisado para finalizar diz respeito a como os estudantes chegam olhando para o universo escolar, como quem tem um conjunto de teorias e como se o campo de estágio fosse um espaço a ser compreendido a partir delas. Daí a nossa dimensão de transformar um olhar que está carregado de preconceitos, e também de indignação - o que é muito potente, pois ao se indignarem estão se posicionando no mundo - para um olhar cúmplice, que esteja mais implicado na escola, que se remete à sua complexidade e se vê como co-produtor daquela realidade.

É neste transformar o primeiro olhar para o campo de futura atuação em um processo de compreensão da que se constrói a potencialidade do trabalho. O instrumento encontrado por nós para esta necessária transformação é o freqüente questionamento sobre o que viveram no estágio, sobre o olhar construído, sobre nossas posturas, nossos valores, sobre nosso necessário agir ético no mundo (KRAMER, 2013). E esta implicação culmina na definição de um projeto de atuação coerente.

\section{Referências}

ARROYO, M. G. Currículo: Territórios em disputa. Rio de Janeiro: Editora Vozes, 2013. . O estágio supervisionado como alternativa à melhoria do ensino. mimeo, 1987.

FREIRE, P.; OLIVEIRA, R. D. Extensão ou comunicação? 12ª ed. Rio de Janeiro, RJ: Paz e Terra, 1983.

FREITAS, L. C. Organização do trabalho pedagógico. Revista de Estudos FEEVALE/ASPEUR. Novo Hamburgo, ano 14, v. 14, n. 1, p. 10-18, julho de 1991.

KRAMER, S. A Educação Como Resposta Responsável: apontamentos sobre o outro como prioridade. In: FREITAS, M. T. (Org.) Educação, Arte e Vida em Bakhtin. Belo Horizonte: Autêntica, 2013. p. 95-106.

RIGHI, E. Reflexão Final de Estágio EP 911. Campinas, SP, 2015 (s.e).

SAMPAIO, R. B. Reflexão Final de Estágio EP 911. Campinas, SP, 2015 (s.e). 
SMOLKA, A. L. B.; LAPLANE, A. O Trabalho em Sala de Aula: Teorias para quê? Caderno ESE, FE/UFF, n. 1, nov./1993. (Alfabetização e Leitura). p. 79-82.

\section{Sobre as autoras}

Adriana Varani é Professora da Faculdade de Educação da Unicamp, orientadora de estágio dos anos iniciais do ensino fundamental no Curso de Pedagogia.

E-mail: drivarani@gmail.com.

Sara Badra de Oliveira é doutoranda na Faculdade de Educação da Unicamp.

E-mail: sarabadra@ hotmail.com. 